\title{
Comparative study of haematological parameters of three sturgeon species in recirculating aquaculture system
}

\author{
NEJDET GULTEPE ${ }^{1}$, MARINA SAZYKINA², IVAN SAZYKIN², ADEM YAVUZ SONMEZ ${ }^{3}$, \\ LUDMILA E. KHMELECTSOVA ${ }^{2}$ AND MARGARITA I. KHAMMAMI ${ }^{2}$ \\ ${ }^{1}$ Department of Genetic and Bioengineering, Engineering and Architecture Faculty, Kastamonu University \\ 37200, Kastamonu, Turkey \\ ${ }^{2}$ Southern Federal University, Research Institute of Biology, Laboratory of Industrial Microorganisms \\ 344006 Rostov on Don, Russia \\ ${ }^{3}$ Kastamonu University, FisheriesFaculty, 37200 Kastamonu, Turkey \\ e-mail: nejdetgultepe@yahoo.com
}

\begin{abstract}
The aim of this study was to evaluate and compare the haematological parameters of cultured Russian sturgeon (Acipenser gueldenstaedtii), stellate sturgeon (Acipenser stellatus) and Siberian sturgeon (Acipenser baerii) in recirculating aquaculture system. Total erythrocytes, thrombocytes, red blood cell distribution, monocytes, basophils as well as haemoglobin levels of stellate sturgeon differed significantly from that of the other two species $(p<0.05)$. Leukocyte and lymphocyte levels of Siberian sturgeon were significantly higher than in stellate sturgeon and Russian sturgeon $(p<0.05)$. Eosinophil percentages of Siberian sturgeon were significantly lower than stellate sturgeon and Russian sturgeon $(p<0.05)$. Haematocrit levels of stellate sturgeon differed from Siberian sturgeon $(\mathrm{p}<0.05)$, but no differences between Siberian and Russian sturgeons were found. Neutrophil, mean cellular haemoglobin and mean cellular volume and mean cellular haemoglobin concentration levels did not differ significantly between the three sturgeon species $(\mathrm{p}>0.05)$. The information generated may help in monitoring health status and to adopt better management strategies in culture systems.
\end{abstract}

Keywords: Fish haematology, Recirculating aquaculture system, Russian sturgeon, Siberian sturgeon, Stellate sturgeon

Acipenser gueldenstaedtii, Acipenser stellatus and Acipenser baerii are the commercially important species of sturgeons most widely cultured. As for all other farmed fish, the health status of sturgeons is important for the sustainability and profitability of farming. Blood parameters are valuable tools for monitoring fish health and welfare status, effects of therapeutic treatments, nutrition as well as environmental management (Blaxhall and Daisley 1973; Hrubec et al., 1996). In aquaculture, blood analyses are rapid, non-lethal and inexpensive way to assess malnutrition, stress, infection status of fish and thus are increasingly used as indicators of the physiological condition or sub-lethal endogenous or exogenous changes and stress response in fish (Cataldi et al., 1998; Belanger et al., 2001). Haematological studies have been performed on most sturgeon species such as Adriatic sturgeon (Acipenser naccarii) (Di Marco et al., 1999), shortnose sturgeon (Acipenser brevirostrum) (Knowles et al., 2006; Matsche et al., 2013), cultured sturgeon hybrids (Acipenser naccarii + X A. baerii ${ }^{\Uparrow}$ ) (Di Marco et al., 2011), Siberian sturgeon (A. baerii) (Sadati et al., 2011), stellate sturgeon (sevruga) (A. stellatus) (Akrami et al., 2013; Khara et al., 2013).
Information on haematological parameters under culture conditions for A. gueldenstaedtii, A. stellatus and $A$. baerii is limited. Aim of the present study was to evaluate and compare haematological parameters of the above three sturgeon species cultured in recirculating aquaculture conditions.

Juveniles of $A$. gueldenstaedtii $(350 \pm 48.22 \mathrm{~g})$, A. stellatus $(205 \pm 65.57 \mathrm{~g})$ and A. baerii $(275 \pm 17.32 \mathrm{~g})$ reared in the farm of Don-Riba Co., Rostovskaya Oblast, Rostov-na-Donu, Russia were used for the experiements. The fishes were stocked in tanks measuring $2 \times 2 \times 2 \mathrm{~m}\left(8 \mathrm{~m}^{3}\right)$, (a) 80 juveniles per tank with three replicates per species. Water flow rate was maintained at approximately $401 \mathrm{~min}^{-1}$. During the experimental period, fish were fed twice daily in mid-morning and mid-afternoon to apparent satiation with commercial fish feed (45:20/protein:fat). During the experimental period, water quality parameters such as dissolved oxygen, $\mathrm{pH}$, temperature, nitrite $\left(\mathrm{NO}_{2}\right)$, nitrate $\left(\mathrm{NO}_{3}\right)$ and ammonia $\left(\mathrm{NH}_{4}\right)$ of the rearing water were measured with a multiparameter probe (Model HQ40d, $\mathrm{HACH}$ Instruments). Total hardness, $\mathrm{HCO}_{3}{ }^{-}$and $\mathrm{Ca}_{2}^{+}$were estimated according to standard methods (APHA, 1998). 
Ten fish from each tank were sampled and anesthetised with tricaine methane sulphonate (MS-222, SIGMA, United States). To reduce stress, the head of fish was covered with a wet towel. Random blood samples from the caudal veins from 10 fish from each tank were collected for haematological analyses with a $20 \mathrm{ml}$ sterile plastic syringe treated with EDTA (Ethylenediaminetetraacetic acid) and sent to laboratory on ice. Total erythrocyte (RBC), leukocyte (WBC), thrombocyte (PLT) counts, red blood cell distribution width (RDW), neutrophils (NEU), lymphocytes (LYM), monocytes (MONO), eosinophils (EOS) and basophils (BAS) counts were determined according to Blaxhall and Daisley (1973), Satake et al. (1986), Jenkins (2003) and Rough et al. (2005). Haematocrit (PCV) values were measured with heparinised microhaematocrit tubes and centrifuged at $10 \times$ gravity for $10 \mathrm{~min}$. The haemoglobin (HGB) content was determined following the technique of Van Kampen and Zijlstra (1961) and Gultepe et al. (2014). Mean cellular haemoglobin (MCH), mean cellular volume (MCV) and mean cellular haemoglobin concentration (MCHC) were determined as described by Klontz (1994) and Gultepe et al. (2012). These parameters were also corrected using an autoanalyser (Beckman Coulter Inc.).

Data were analysed using STATISTICA (Version 6.0) (StatSoft, Inc.). Statistical differences were evaluated using one-way analysis of variance (ANOVA) followed by Fisher's least significant difference (LSD) test for multiple pair-wise comparisons. Statistically significant differences were accepted at $\mathrm{p}<0.05$.

Physico-chemical characteristics of the water recorded during the experimental period were: dissolved oxygen - $7.8 \pm 0.22 \mathrm{mg} \mathrm{l}^{-1} ; \mathrm{pH}-7.7 \pm 0.8$; temperature - $14 \pm 1^{\circ} \mathrm{C} ; \mathrm{NO}_{2}-0 \mathrm{mg} \mathrm{1^{-1 }} ; \mathrm{NO}_{3}-7.1 \pm 0.4 \mathrm{mg} \mathrm{l}^{-1}$; $\mathrm{NH}_{4}-0.40 \pm 0.10 \mathrm{mg} \mathrm{l}^{-1} ; \mathrm{HCO}_{3}^{-}-2.09 \pm 0.14 \mathrm{mg} \mathrm{l}^{-1} ; \mathrm{Ca}_{2}^{+}$$2.40 \pm 0.1$ milliequivalent $\mathrm{l}^{-1}$ and total hardness - $100 \mathrm{ppm}$ as $\mathrm{CaCO}_{3}$.

Haematological parameters recorded for the three species of sturgeons during the experimental period are presented in Table 1. RBC, PLT, RDW, MONO, BAS and HGB levels in A. stellatus were significantly different, compared to A. gueldenstaedtii and A. baerii $(\mathrm{p}<0.05)$. WBC and LYM levels of Siberian sturgeon were significantly higher than that of stellate and Russian sturgeons $(p<0.05)$. EOS percentages of Siberian sturgeon were significantly lower than stellate sturgeon and Russian sturgeon $(p<0.05)$. MCHC and PCV levels of stellate sturgeon differed from Siberian sturgeon $(p<0.05)$, but no differences were observed between Siberian and Russian sturgeons. NEU, MCH and MCV levels of three sturgeon species were not significantly different ( $p>0.05)$, which is an important observation in the present study.
Table 1. Comparison of hematological parameters between the three sturgeon species

\begin{tabular}{|c|c|c|c|}
\hline \multirow{2}{*}{ Parameter } & \multicolumn{3}{|c|}{ Species } \\
\hline & A. stellatus & A. gueldenstaedtii & A. baerii \\
\hline $\operatorname{RBC}\left(\mathrm{M} \mathrm{ul}^{-1}\right)$ & $0.74 \pm 0.09^{\mathrm{a}}$ & $0.49 \pm 0.12^{\mathrm{b}}$ & $0.34 \pm 0.31^{\mathrm{b}}$ \\
\hline WBC $\left(\mathrm{K} \mathrm{ul}^{-1}\right)$ & $2.47 \pm 0.75^{\mathrm{a}}$ & $7.08 \pm 5.62^{\mathrm{a}}$ & $16.28 \pm 9.81^{\mathrm{b}}$ \\
\hline $\operatorname{PLT}\left(\mathrm{K} \mathrm{ul}^{-1}\right)$ & $1.139 \pm 133.05^{\mathrm{a}}$ & $410.33 \pm 179.63^{b}$ & $451.50 \pm 329.72^{b}$ \\
\hline RDW (\%) & $26.77 \pm 0.76^{\mathrm{a}}$ & $12.87 \pm 6.89^{\mathrm{b}}$ & $9.23 \pm 2.69^{\mathrm{b}}$ \\
\hline NEU (\%) & $0.06 \pm 0.03$ & $0.08 \pm 0.07$ & $0.10 \pm 0.07$ \\
\hline LYM (\%) & $1.01 \pm 0.40^{\mathrm{a}}$ & $5.93 \pm 4.99^{\mathrm{a}}$ & $15.67 \pm 9.55^{\mathrm{b}}$ \\
\hline MONO (\%) & $0.21 \pm 0.08$ & $0.28 \pm 0.06$ & $0.27 \pm 0.06$ \\
\hline EOS (\%) & $1.40 \pm 0.96^{\mathrm{a}}$ & $1.01 \pm 1.00^{\mathrm{a}}$ & $0.19 \pm 0.18^{\mathrm{b}}$ \\
\hline BAS (\%) & $0.05 \pm 0.01$ & $0.07 \pm 0.01$ & $0.06 \pm 0.03$ \\
\hline PCV (\%) & $10.30 \pm 1.96^{\mathrm{a}}$ & $8.74 \pm 1.68^{\mathrm{ab}}$ & $6.47 \pm 1.10^{\mathrm{b}}$ \\
\hline $\mathrm{HGB}\left(\mathrm{g} \mathrm{dl}^{-1}\right)$ & $4.89 \pm 3.73^{\mathrm{a}}$ & $7.91 \pm 1.12^{\mathrm{b}}$ & $8.13 \pm 3.82^{b}$ \\
\hline MCH (pg) & $138.66 \pm 9.60$ & $148.00 \pm 30.81$ & $98.20 \pm 29.27$ \\
\hline MCV (fl) & $138.67 \pm 9.61$ & $148.00 \pm 19.48$ & $98.20 \pm 23.90$ \\
\hline $\operatorname{MCHC}\left(\mathrm{g} \mathrm{dl}^{-1}\right)$ & $70.30 \pm 6.02^{\mathrm{a}}$ & $106.53 \pm 48.21^{\mathrm{ab}}$ & $168.00 \pm 36.00^{\mathrm{b}}$ \\
\hline
\end{tabular}

$\mathrm{RBC}=$ total erythrocyte count, $\mathrm{WBC}=$ leukocyte count, $\mathrm{PLT}=$ thrombocyte count, RDW = red blood cell distribution width, $\mathrm{NEU}=$ neutrophils, $\mathrm{LYM}=$ lymphocyte count, $\mathrm{MONO}=$ monocytes, $\mathrm{EOS}=$ eosinophils, $\mathrm{BAS}=$ basophils, $\mathrm{PCV}=$ hematocrit, $\mathrm{HGB}=$ hemoglobin, $\mathrm{MCH}=$ mean cellular hemoglobin, $\mathrm{MCV}=$ mean cellular volume, $\mathrm{MCHC}=$ mean cellular hemoglobin concentration. The values are expressed as mean \pm SD $(n=30)$. Means with different superscripts in rows are significantly different $(\mathrm{p}<0.05)$

Sturgeon species are grown in farms for caviar and meat. Generally, producers prefer recirculating aquaculture systems for healthy fish production and to eliminate environmental risks. Blood parameters give information on both physiological condition and health of fish. In individual fish, genetic variation, age, stage of development and reproductive stage have been determined using the haematological values (Hrubec et al., 1996). Although reference intervals have been determined for Siberian sturgeon (A. baerii) (Sadati et al., 2011) and stellate sturgeon (A. stellatus) (Akrami et al., 2013; Khara et al., 2013), there is no study on comparison of haematological values of the three sturgeon species under study. These studies are useful to determine effects of environmental and nutritional factors on species and effective management of aquaculture facilities. PCV (or HCT) is the most important haematological parameter in fishes to assess health and nutritional status of species (Klontz and Smith, 1968; Campbell, 2004). Blaxhall and Daisely (1973) have reported on the possible use of PCV value as a tool to determine anaemia. PCV values in fish generally ranges from 20 to $45 \%$. These values were not in line with our data. The significant differences in PCV values could be attributed to different habitat conditions or feeding. HGB values in fishes generally range from 5 to $10 \mathrm{mg} \mathrm{dl}^{-1}$ (Hrubec and Smith, 2000). In the present study, HGB levels ranged from $7.91 \pm 1.12$ to $8.13 \pm 3.82$ for Russian sturgeon and Siberian surgeon, respectively. But we found that HGB level of stellate sturgeon was significantly lower than others. Similarly, reduced 
HGB values may be attributed to changes in circulating erythrocytes numbers (Zarejabad et al., 2010). According to Hrubec and Smith (2000) MCV, MCH and MCHC values of fishes range from 150 to $350 \mathrm{fl}, 30$ to $100 \mathrm{pg}$ and 18 to $30 \%$ respectively. The high values of $\mathrm{MCH}$ (171 pg) and MCHC (204 $\left.\mathrm{g} \mathrm{dl}^{-1}\right)$ recorded for the three sturgeon species in this study could be due to the overall oxygen consumption rates and swimming performance under normal conditions (Stillwell and Benfey, 1995). $\mathrm{MCH}$ and $\mathrm{MCV}$ values were found almost similar for the three sturgeon species in the present study. Leucocytes are important cells that can stimulate immune responses in fish. These cells produce antibodies and can perform macrophagic activities (Jalali et al., 2009). The differences in WBC count observed in the three sturgeon species in this study may be attributed to the varying body size of experimental fish (Xiaoyun et al., 2009). Changes in white blood cells and the differential counts, neutrophils, lymphocytes and monocytes indicated stress condition in fish (Gabriel et al., 2011). In the present study, there were no significant difference on NEU, MONO and LYM values among three sturgeon species. RDW level for stellate sturgeon was higher than in Russian and Siberian sturgeons. These results suggest that sturgeon producers must take into consideration ferrous level of feed, especially for stellate sturgeon.

In this research, haematological parameters of A. gueldenstaedtii, A. stellatus and A. baerii were compared for the first time in recirculating aquaculture system. The results showed that some haematological parameters can be similar under same culture conditions for different sturgeon species. Also results suggested that sturgeon producers must take into consideration ferrous level of feed, especially for stellate sturgeon. The information generated may help in monitoring health, nutritional and welfare status of fish; to adopt better management strategies with respect to stocking density, feed and water quality as well as in disease control in culture systems.

\section{Acknowledgements}

This study was funded by the Southern federal university (grant No. 213.01-07-2014/12PChVG), № 213-01 / 2015-05VG (2B) and RF President's grant (No. nSh-9072.2016.11) for the state support of leading scientific schools of the Russian Federation.

\section{References}

Akrami, R., Iri, Y., Rostami, H. K. and Mansour, M. R. 2013. Effect of dietary supplementation of fructooligosaccharide (FOS) on growth performance, survival, Lactobacillus bacterial population and hemato-immunological parameters of stellate sturgeon (Acipenser stellatus) juvenile. Fish Shellfish Immunol., 35: 1235-1239.
APHA 1998. Standard methods for the examination of water and wastewater, $20^{\text {th }}$ edn. American Public Health Association, Washington, DC, USA.

Belanger, J. M., Son, J. H., Laugero, K. D., Moberg, G. P., Dorochov, S. I., Lankford, S. E. and Cech Jr. J. J. 2001. Effects of short term management stress and ACTH injections on plasma cortisol levels in cultured white sturgeon, Acipenser transmontanus. Aquaculture, 203: $165-176$.

Blaxhall, P. C. and Daisley, K. W. 1973. Routine hematological methods for use with fish blood. J. Fish Biol., 5: 771-781.

Campbell, T. W. 2004. Hematology of fish. In: Troy, D. B. (Ed.), Veterinary and clinical chemistry. Williams \& Wilkins, Baltimore, p. 277-289.

Cataldi, E., Di Marco, P., Mandich, A. and Cataudella, S. 1998. Serum parameters of Adriatic sturgeon Acipenser naccarii (Pisces: Acipenseriformes). Effects of temperature and stress. Comp. Biochem. Physiol., 120: 273-278.

Di Marco, P., McKenzie, D. J., Mandich, A., Bronzi, P., Cataldi, E. and Cataudella, S. 1999. Influence of sampling conditions on blood chemistry values of Adriatic sturgeon Acipenser naccarii (Bonaparte, 1836). J. Appl. Ichthyol., 15: 73-77.

Di Marco, P., Priori, A., Finoia, M. G., Petochi, T., Longobardi, A., Donadelli, V. and Marino, G. 2011. Assessment of blood chemistry reference values for cultured sturgeon hybrids (Acipenser naccarii female $\mathrm{x}$ Acipenser baerii male). J. Appl. Ichthyol., 27: 584-590.

Francis-Floyd, R. 2000. Diseases history of cultured sturgeon in Florida, 1990-1999, Proceedings of the Florida sturgeon culture risk assessment workshop, p. 33-37.

Gabriel, U. U., Akinrotimi, O. A. and Eseimokumo, F. 2011. Haematological responses of wild Nile tilapia Oreochromis niloticus after acclimation to captivity. Jordan J. Biol, Sci., 4(4): 225-230.

Gultepe, N., Hisar, O., Salnur, S., Hossu, B., Tanrikul, T. T. and Aydin, S. 2012. Preliminary assessment of dietary mannanoligosaccharides on growth performance and health status of gilthead seabream Sparus auratus. J. Aquatic Anim. Health, 24: 37-42.

Gultepe, N., Bilen, S., Yilmaz, S., Guroy, D. and Aydin, S. 2014. Effects of herbs and spice on health status of tilapia (Oreochromis mossambicus) challenged with Streptococcus iniae. Acta Veterinaria BRNO, 83: 125-131.

Hrubec, T. C., Smith, S. A., Robertson, J. L., Veit, H. P., Libey, G. and Tinker, M. K.1996. Comparison of hematologic reference intervals between culture system and type of hybrid striped bass. American J. Vet. Res., 57: 618-623.

Hrubec, T. C. and Smith, S. A. 2000. Hematology of fish. In: Feldman, B. F., Zink1, J. G. and Jain, N. C. (Eds.), Schalm's Veterinary Hematology, $5^{\text {th }}$ edn. Williams \& Wilkins, Philadelphia, p. 1120-1125. 
Jalali, M. A., Ahmadifar, E., Sudagar, M. and Takami, G. A. 2009. Growth efficiency, body composition, survival and haematological changes in great sturgeon (Huso huso Linnaeus, 1758) juveniles fed diets supplemented with different levels of Ergosan. Aquac. Res., 40: 804-809.

Jenkins, J. A. 2003. Pallid sturgeon in the lower Mississippi region: Hematology and genome information. USGS Open file report, 03-406, $32 \mathrm{pp}$.

Khara, H., Falahatkar, B., Meknatkhah, B., Ahmadnezhad, M., Efatpanah, I., Poursaeid, S. and Rahbar, M. 2013. Effect of dietary estradiol $17 \beta$ on growth, haematology and biochemistry of stellate sturgeon Acipenser stellatus. World J. Fish. Mar. Sci., 5(2): 113-120.

Klontz, G. W. and Smith, L. S. 1968. Methods of animal experimentation, vol. 3. Academic Press Inc., New York, p. 323-385.

Klontz, G, W. 1994. Fish hematology. In: Stolen, J. S., Fletcher, T. C., Rowley, A. F., ZelikoffJ, T., Kaattari, S. L. and Smith, S. A. (Eds.), Techniques in fish immunology, Volume III. SOS Publications, Fair Haven, New Jersey, p. 121-131.

Knowles, S., Hrubec,T. C., Smith, S. A. and Bakal, R. S. 2006. Hematology and plasma chemistry reference intervals for cultured shortnose sturgeon (Acipenser brevirostrum). Vet. Clinical Pathol., 35(4): 434-440.

Matsche, M. A., Rosemary, K. M., Brundage III H. M. and O'herron II J. C. 2013. Hematology and plasma chemistry of wild shortnose sturgeon Acipenser brevirostrum from Delaware River, USA. J. Appl. Ichthyol., 29: 6-14.

Rough, K. M., Nowak, B. F. and Reuter, R. E. 2005. Haematology and leucocyte morphology of wild caught Thunnus maccoyii. J. Fish Biol., 66: 1649-1659.
Sadati, M. A. Y., Pourkazemi, M., Shakurian, M., Hasani, M. H. S., Pourali, H. R., Pourasaadi, M. and Yousefi, A. 2011. Effects of daily temperature fluctuations on growth and hematology of juvenile Acipenser baerii. J. Appl. Ichthyol., 27: 591-594.

Satake, T., Nuti-Sobrinho, A, Paula-Lopes, O. V., Lopes, R. A. and Santos, HSLD. 1986. Haematological study of Brazilian fish: III. blood parameters in armored catfish Hypostomus paulinus IHERING 1905 (Pisces, Loricariidae). Ars Veterinaria, 2: 179-183.

Stillwell, E. J. and Benfey, T. J. 1995. Haemoglobin level, metabolic rate and swimming performance of triploid brooktrout Salvelinus fontinalis. Aquacuture, 137: 355-358.

Tanrikul, T. T. and Gultepe, N. 2011. Mix infections in rainbow trout (Oncorhynchus mykiss Walbaum): Lactococcus garvieae and Vibrio anguillarum O1. J. Animal Vet. Advances, 10(8): 1019-1023.

Van Kampen, E. J. and Zijlstra, W. G. 1961. Standardisation of hemoglobinometry II. The hemiglobincyanide method. Clinica Chimica Acta, 6(4): 538-544.

Xiaoyun, Z., Mingyun, L., Khalid, A. and Weinmin, W. 2009. Comparison of haematology and serum biochemistry of cultured and wild Dojo loach Misgurnus angullicadatus. Fish Physiol. Biochem., 35: 435-441.

Zarejabad, A. M., Jalali, A. A., Sudagar, M. and Pouralimotlagh, S. 2010. Hematology of great sturgeon (Huso huso Linnaeus, 1758) juvenile exposed to brackishwater environment. Fish Physiol. Biochem., 36: 655-659. 